Research Article

\title{
Self-recognition and $\mathrm{Ca}^{2+}$-dependent Carbohydrate-carbohydrate
}

\section{Cell Adhesion Provide Clues to the Cambrian Explosion}

\author{
Xavier Fernàndez-Busquets, ${ }^{*}+$ † André Körnig, ${ }^{*} \S$ Iwona Bucior, †ๆ Max M
}

Burger, $\dagger \|$ and Dario Anselmetti§

*Nanobioengineering Group, Institute for Bioengineering of Catalonia, and Biomolecular

Interactions Team, Nanoscience and Nanotechnology Institute, Barcelona Science Park, University of Barcelona, E 08028 Barcelona, Spain; † Marine Biological Laboratory, Woods Hole, MA 02543; §Experimental Biophysics and Applied Nanoscience, Bielefeld University, D 33615 Bielefeld, Germany; ๆUniversity of California San Francisco, San Francisco, CA 94143; and $\|$ Friedrich Miescher Institute for Biomedical Research, Novartis Research Foundation, Novartis International AG, CH 4002 Basel, Switzerland.

†Address correspondence to: Xavier Fernàndez-Busquets, Institute for Bioengineering of Catalonia, Barcelona Science Park, Baldiri Reixac 10-12, E 08028 Barcelona, Spain. Tel.: +34934037180; fax: +34934037181 .

E-mail: xfernandez_busquets@ub.edu, Dario.Anselmetti@physik.uni-bielefeld.de.

Key words: calcium, Cambrian explosion, carbohydrates, cell adhesion, origin of Metazoa, sponges.

Running head: Calcium-mediated cell adhesion in animal evolution

Abbreviations: AF, aggregation factor; DFS, dynamic force spectroscopy; MAF, Microciona prolifera AF; SMFS, single molecule force spectroscopy. 


\section{Abstract}

The Cambrian explosion of life was a relatively short period ca. 540 million years ago that marked a generalized acceleration in the evolution of most animal phyla, but the trigger of this key biological event remains elusive. Sponges are the oldest extant Precambrian metazoan phylum and thus a valid model to study factors that could have unleashed the rise of multicellular animals. One such factor is the advent of self/non-self recognition systems, which would be evolutionarily beneficial to organisms to prevent germ cell parasitism or the introduction of deleterious mutations resulting from fusion with genetically different individuals. However, the molecules responsible for allorecognition probably evolved gradually before the Cambrian period, and some other (external) factor remains to be identified as the missing triggering event. Sponge cells associate through calcium-dependent, multivalent carbohydrate-carbohydrate interactions of the g200 glycan found on extracellular proteoglycans. Single molecule force spectroscopy analysis of g200-g200 binding indicates that calcium affects the lifetime $(+\mathrm{Ca} /-\mathrm{Ca}$ : $680 \mathrm{~s} / 3 \mathrm{~s})$ and bond reaction length (+Ca/-Ca: $3.47 \AA / 2.27 \AA)$. Calculation of mean g200 dissociation times in low and high calcium within the theoretical framework of a cooperative binding model indicates the non-linear and divergent characteristics leading to either disaggregated cells or stable multicellular assemblies, respectively. This fundamental phenomenon can explain a switch from weak to strong adhesion between primitive metazoan cells caused by the well documented rise in ocean calcium levels at the end of Precambrian time. We propose that stronger cell adhesion allowed the integrity of genetically uniform animals composed only of "self" cells, facilitating genetic constitutions to remain within the metazoan individual and be passed down inheritance lines. The Cambrian explosion might have been 
triggered by the coincidence in time of primitive animals endowed with self/non-self recognition, and of a surge in sea water calcium that increased the binding forces between their calciumdependent cell adhesion molecules. 


\section{Introduction}

The Cambrian explosion is widely regarded as one of the most relevant episodes in the history of life on Earth (Conway-Morris, 2006), when about half of living animal phyla first appear in the fossil record, and yet, its origins and causes remain controversial (Marshall, 2006). It is not obvious why a greater speed in evolution could be beneficial by itself, and more likely it was a consequence of some other factor directly linked to evolutionary pressure. One of the phenomena more generally accepted as a principal force of selection is the "selfish" competition for passing down one's genotype (Dawkins, 1976), and not that of others. The development of self/non-self recognition in primitive metazoans might have been a necessary innovation to prevent interindividual cell parasitism, at the expense of reducing resistance to environmental variations as a result of increased genetic variability (Buss, 1982). Somatic and germ cell parasitism is a natural transplantation reaction of certain colonial ascidians, that results alternatively in colony fusion or inflammatory rejection in a process regulated by a highly polymorphic histocompatibility locus (Stoner and Weissman, 1996). Because this allorecognition system limits fusion to close relatives, it may have evolved as a mechanism to minimize the fitness costs of chimera formation (Buss, 1982). Fusion with conspecifics could confer benefits by gaining wider ranges of physiological resistance and increasing the size of the resulting chimera, which in turn limit susceptibility to the impact of ecological processes and favor reproductive output. However, because all genotypes in a chimera have access to the production of gametes, one genotype can functionally parasitize other members of the chimera by contributing disproportionately to gamete production (Buss, 1982;Feldgarden and Yund, 1992). In analogy to this contemporary ascidian allogeneic recognition, a situation can be envisaged where a fertilized egg from a primitive metazoan carrying a new gene that would impact 
negatively upon organismal fitness divides to form a free-swimming larva that settles down on the sea floor. In the absence of individual recognition developing larvae that make contact through growth or crawling can merge and develop as chimeras. In this scenario the detrimental effect would be maintained in the offspring through fusion with individuals lacking the negative mutation (fig. 1A). Viable chimeras have been observed to form between juveniles of the sponge Amphimedon queenslandica, provided that fusion takes place during the first two weeks after hatching (Gauthier and Degnan, 2008), a process that could be the remnant of an ancient system permitting intraspecific somatic cell intermingling. On the other hand, if allorecognition exists, encounters between genetically different clones will result in non-fusion (fig. 1B), thus preventing the incorporation of new fitness-reducing genes. This might lead to an accelerated evolutionary rate by favoring the existence of individuals better adapted to the environment that could have more abundant offsprings.

In marine sponges, the oldest extant Precambrian metazoan phylum, dissociated cells have the capacity to species-specifically sort out and reaggregate through calcium-dependent associations of cell surface proteoglycans termed aggregation factors (AFs, fig. 2) (FernàndezBusquets and Burger, 2003), similarly as mixtures of dissociated vertebrate embryonic cells sort out according to their tissue of origin (Steinberg and Garrod, 1975). In the marine sponge Microciona prolifera, the AF proteins MAFp3 and MAFp4 are encoded by a highly polymorphic gene, and grafting experiments revealed that histoincompatible Microciona individuals invariably have dissimilar MAFp3 and MAFp4 composition according to Southern blot data (FernàndezBusquets and Burger, 1997). This led us to suggest that the AF, or a closely related molecule, could be the allogeneic determinant of sponge self/non-self recognition (Fernàndez-Busquets and Burger, 2003;Fernàndez-Busquets and Burger, 1999), that arguably was one of the first allorecognition systems to evolve in animals given that sponges may be at the basis of the 
metazoan phylogenetic tree (Dunn et al., 2008). However, the first sponges preceded the Cambrian explosion by at least a hundred million years (Myr) (Budd, 2008;Love et al., 2009). This time expanse was long enough to develop a rich palette of genes that genetic studies are identifying in sponges, which rival the complexity of vertebrate genomes (Sakarya et al., 2007;Müller, 2001;Müller et al., 2001;Fernàndez-Busquets, 2008). Sponges possess elements involved in transplantation immunity that are key components of mammalian innate immunity (Müller and Müller, 2003), including molecules containing scavenger receptor cysteine-rich domains (Pahler et al., 1998), Toll-like receptors (Wiens et al., 2007), the (2',5')oligoadenylate synthetase (Kuusksalu et al., 1995), cytokine-like molecules (Müller et al., 1999), and also factors similar to those synthesized by cytokine-responsive macrophage molecules such as the allograft inflammatory factor 1 (Kruse et al., 1999). The immunoglobulin-like domain, a hallmark of adaptive immune systems, has been identified in sponges (Blumbach et al., 1999), in some cases exhibiting intraspecific polymorphism (Pancer et al., 1998). Finally, allogeneic recognition in sponges has been found to be mediated by a specific cell type through mechanisms similar to those governing similar processes in vertebrates (Fernàndez-Busquets et al., 2002;Sabella et al., 2007). Hardly could such a refined machinery have appeared almost overnight in the geological time scale. Thus, another event was necessary in addition to the advent of self/non-self recognition for the Cambrian explosion to occur. Some proposed factors such as the origin of bilaterian body plans and the development of vision were in all likelihood later events. Sudden changes in the biosphere are often related to environmental factors, several of which have been proposed as the trigger event of the Cambrian explosion (Conway-Morris, 2006;Marshall, 2006), including a worldwide massive glaciation, an increase in the sophistication of predatory strategies, ecological niche saturation, or alterations in the chemistry of the oceans such as a rise in oxygen levels or a modification in the composition of sea water, but none of them has provided 
so far a sufficiently satisfactory explanation.

Sponge AFs are bifunctional molecules exhibiting a $\mathrm{Ca}^{2+}$-independent interaction with cell membrane receptors and $\mathrm{Ca}^{2+}$-dependent self-binding activity. In M. prolifera, the AF selfbinding site has been tracked down to g200, a complex glycan of $200 \mathrm{kDa}$ (Misevic et al., 1987;Jarchow et al., 2000;Bucior et al., 2004). The polyvalency of g200 on an AF molecule permits the integration of multiple individual binding sites into a much stronger bond (fig. $3 A, B$ ). Most functional studies of sponge cell adhesion have been done at the current sea water $\mathrm{Ca}^{2+}$ concentration of $10 \mathrm{mM}$, but little attention has been placed on investigating possible implications of adhesion forces in low calcium (Rice and Humphreys, 1983). To quantitatively explore the significance of changing $\mathrm{Ca}^{2+}$ concentrations on the association of primitive metazoan cells, we have performed a comparative single molecule force spectroscopy (SMFS) study of g200 self-binding in low and high $\mathrm{Ca}^{2+}$, analyzing the data in the context of a multivalent system model. Our results are discussed within the framework of the ongoing discussion about which factor(s) triggered the Cambrian explosion of life. 


\section{Materials and Methods}

Atomic force microscope (AFM) imaging

AFM images were acquired with the commercial instrument Nanoscope III (Multimode and Bioscope AFM, Digital Instruments, Santa Barbara, CA). Imaging was done in tapping mode of operation under ambient conditions with standard Si cantilevers (Nanoprobe, Wetzlar, Germany). Sample preparation was always according to our standard protocols (Fritz et al., 1997) or according to the protocols using $\mathrm{NH}_{2}$-functionalized mica substrates (Lyubchenko et al., 1993).

\section{SMFS assays}

A solution containing $1 \mu \mathrm{M}$ of purified g200 (Garcia-Manyes et al., 2006) and $1 \mu \mathrm{M} \mathrm{N}$ hydroxysuccinimide-poly(ethylene glycol)-maleimide (NHS-PEG-MAL 3,400, Nektar Therapeutics) in deionized water was incubated for $5 \mathrm{~h}$ at $4^{\circ} \mathrm{C} . \mathrm{Si}_{3} \mathrm{~N}_{4}$ cantilevers (Microlever, Veeco Instruments) and mica surfaces (Provac AG) were silanized with aminopropyltriethoxysilan (Sigma Aldrich) in an exsiccator and then overlaid with the g200-PEG linker solution at $4^{\circ} \mathrm{C}$ overnight. After washing with $\mathrm{H}_{2} \mathrm{O}$, cantilevers and surfaces were ready for use in force spectroscopy experiments. Several cantilevers and surfaces were prepared simultaneously to ensure maximum immobilization homogeneity. Freshly prepared tips and surfaces were used in each experiment. SMFS measurements were performed with a commercial AFM (MFP3D, Asylum Research) at room temperature in calcium and magnesium-free artificial seawater prepared according to the standards of the Marine Biological Laboratory (www.mbl.edu), with or without $10 \mathrm{mM} \mathrm{CaCl}_{2}$. The spring constant of the cantilever was calibrated by the thermal fluctuation method (Hutter and Bechhofer, 1993) and the same 
cantilever was used in each experiment for both plus and minus calcium conditions. Typically 2,000-3,000 force curves were recorded at four different retracting velocities while the approach velocity was kept constant. The order in which the velocities were applied did not influence the results. When the same tip and surface were used with and without calcium (in either order) the results were equivalent to those obtained with a different tip/surface combination for each condition. The curves were analyzed with a Matlab-based analysis software (Math Works), corrected to display the actual molecular extension calculated from the $z$ piezo extension, and plotted in force histograms (fig. S1) where the maximum of the force probability distribution is referred to as dissociation force $\left(F_{\max }\right)$.

\section{Calcium uptake assays}

Live sponge cells and g200 glycan preparation, and aggregation inhibition by Block 2 monoclonal antibody were done as previously described (Misevic et al., 1987). Coupling of g200 to amine-modified 1- $\mu \mathrm{m}$ latex beads (Molecular Probes), and cell- and bead-aggregation assays were done as specified before (Bucior et al., 2004). Calcium uptake was estimated for cell-cell and g200-coated bead-bead aggregation. $5 \times 10^{3} \mathrm{M}$. prolifera cells $/ \mathrm{mL}$ or $9 \times 10^{7} \mathrm{~g} 200$-coated amine-modified beads $/ \mathrm{mL}$ were allowed to aggregate on a rotary shaker at $60 \mathrm{rpm}$ in calciumand magnesium-free Tris-buffered sea water containing $10 \mathrm{mM} \mathrm{CaCl}_{2}$ labeled with ${ }^{45} \mathrm{Ca}$ (74 MBq, $2 \mathrm{mCi}$, AmershamPharmaciaBiotech). After different times of incubation, cells or beads were spun down $(1,000 \times g, 5 \mathrm{~min})$. The amount of ${ }^{45} \mathrm{Ca}$ remaining in solution was quantified in a liquid scintillation counter (Beckmann LS 3801) and subtracted from the initial radioactivity to determine the percentage of $\mathrm{Ca}^{2+}$ taken by aggregating cells or glycan-coated beads. 


\section{Results}

We performed g200-g200 atomic force microscope SMFS assays using a well established method for the immobilization of biomolecules via a heterobifunctional polyethylene glycol linker (Hinterdorfer et al., 1996). Such strategy introduces a distance between interacting molecules and surfaces (fig. 3C), adds steric flexibility for the binding partners, and guarantees an almost complete reduction of unspecific binding events (Eckel et al., 2005). The results obtained in calcium-free artificial seawater indicate the existence of relatively strong forces between 100 and 200 picoNewton (pN) for the g200-g200 interaction (fig. S1). These forces being of the same order of magnitude as those obtained for the same molecule in the presence of $10 \mathrm{mM} \mathrm{Ca}^{2+}$, one would expect that AFs could aggregate cells in the absence of calcium. This, however, contradicts the well-established fact that the multicellular integrity of contemporary seawater sponges is lost below a critical calcium concentration threshold (Fernàndez-Busquets and Burger, 2003;Rice and Humphreys, 1983). Thus, absolute binding forces can not be used as the dominating factor to explain the carbohydrate-mediated interaction between sponge cells.

According to the standard model of thermally driven dissociation under external force (Evans and Ritchie, 1997), the measured dissociation forces $\left(F_{\max }\right)$ depend on the experimental retract velocity and should be represented against the corresponding molecular loading rates in a dynamic force spectroscopy (DFS) plot. To obtain molecular loading rates, the retract velocity is multiplied by the elasticity of the system, which is determined by fitting the slope of every single force curve just before dissociation. Generally, the measured $F_{\max }$ obeys the following law:

$$
F_{\max }=\frac{k_{B} T}{x_{\beta}} \ln \frac{x_{\beta} r}{k_{B} T k_{\text {off }}}
$$


where $k_{B} T$ and $r$ denote thermal energy and the loading rate, respectively. $x_{\beta}$ is a length parameter along the reaction coordinate representing the distance between the minimum of the binding potential and the transition state separating bound and free states, which is commonly referred to as the reaction length. $k_{\text {off }}$ is the thermal off-rate constant under zero external load and can be deduced by linearly extrapolating the experimental data in the DFS plot to zero external force $(F=0)$. It has already been shown earlier (Schwesinger et al., 2000) that estimated $k_{\text {off }}$ in single molecule experiments can unequivocally be assigned with kinetic data extracted from molecular ensemble experiments. The inverse relation of $k_{\text {off }}$ to the average lifetime of the complex, $\tau\left(k_{o f f}=\tau^{-1}\right)$, allows a direct way of evaluating the stability of the complex. The logarithmic DFS plot of our measured SMFS data (fig. 3D) yields the expected linear dependence according to equation [1]. A clear and significant difference between the experiments with (10 $\mathrm{mM})$ and without $(0 \mathrm{mM}) \mathrm{Ca}^{2+}$ can be inferred. For the single molecule process, quantitative analysis yields dissociation rate constants of $k_{\text {off,s.m. } .}\left(+\mathrm{Ca}^{2+}\right)=1.47 \pm 1.23 \times 10^{-3} \mathrm{~s}^{-1}$ and $k_{\text {off.s.m. }}\left(-\mathrm{Ca}^{2+}\right)=0.38 \pm 0.24 \mathrm{~s}^{-1}$, and reaction lengths of $x_{\beta}\left(+\mathrm{Ca}^{2+}\right)=3.47 \pm 0.44 \AA$ and $x_{\beta}\left(-\mathrm{Ca}^{2+}\right)$ $=2.27 \pm 0.15 \AA$.

Thus, in $0 \mathrm{mM}$ calcium (fig. 4A) the mean g200-g200 reaction length falls below the hydrogen bond distance in biomolecules, which is around $2.9 \AA$ between the centers of donor and acceptor atoms (Mathews and van Holde, 1990), whereas in the presence of $10 \mathrm{mM}$ calcium (fig. $4 B)$ the mean reaction length increases to well above the hydrogen bond range. When sponge cells or g200-coated beads are allowed to aggregate in $10 \mathrm{mM} \mathrm{CaCl}_{2}$ there is a significant calcium uptake from the medium by the glycan structures (fig. S2), which is abolished in the presence of a monoclonal antibody against a species-specific g200 self-adhesion epitope (Misevic and Burger, 1993). This sequestering of calcium is not immediate, suggesting that the cation 
becomes gradually incorporated into the glycan structure in a time-dependent process. Because the reciprocal effect of calcium leakage from g200 in a calcium-free environment is also expected to be gradual, glycan-bound $\mathrm{Ca}^{2+}$ ions are likely responsible for a significant fraction of the interaction measured by SMFS at the nominal concentration of $0 \mathrm{mM} \mathrm{Ca}^{2+}$. The known unability of g200 to aggregate cells in the absence of calcium might lead to the conclusion that calcium is required simply to provide forces stronger than hydrogen bonds between the carbohydrate chains. However, other cations such as $\mathrm{Na}^{+}$and $\mathrm{Mg}^{2+}$ can not substitute for $\mathrm{Ca}^{2+}$ (Rice and Humphreys, 1983), suggesting additional binding elements other than purely ionic interactions. Calcium ions could be responsible for the approach and organization of the sugar moieties which provide the adequate surfaces for interaction, or may also enhance the adhesion between complementary surfaces through a suitable configuration of hydroxyl groups. Single hydroxyl groups in sugars are too weak to coordinate cations in the presence of water molecules, although with the combination of two to three adequately positioned hydroxyls on one sugar residue or over two adjacent residues, calcium ions can become coordinated to electron pair donor groups on the carbohydrates (Spillmann and Burger, 1996), either directly or through intervening water molecules, all of which would result in increased reaction lengths (fig. 4B).

There is a second parameter that can be derived from SMFS data having profound evolutionary implications related to the polyvalent calcium-dependent association of sponge cells to form a multicellular animal. The mean lifetime of the g200-g200 binding, $\tau_{\text {s.m. }}\left(1 / k_{\text {off.s.m. }}\right)$, is much increased in the presence of $10 \mathrm{mM}$ calcium: 680 vs. $2.6 \mathrm{~s}$ in its absence. For a given binding force between two ligands, the time during which the interaction takes place will have dramatic consequences on its outcome. A rapid on/off switching between bound and unbound states will be more prone to dissociation than a much more stable association. In addition, slow 
on/off rates will favor the adequate positioning of coordinating lock-and-key epitopes that might account for the specificity of the interaction. Marine sponges like M. prolifera can keep for years $\left(>10^{7} \mathrm{~s}\right)$ their multicellular integrity in seawater containing $10 \mathrm{mM} \mathrm{Ca}^{2+}$ and start to dissociate within minutes $\left(<10^{2} \mathrm{~s}\right)$ in the absence of $\mathrm{Ca}^{2+}$, whereas the corresponding $\mathrm{Ca}^{2+}$-dependent g200 interaction on a single molecule level only exhibits lifetimes of about $10^{3}$ and $1 \mathrm{~s}$, respectively. This disparity in lifetimes by several orders of magnitude can be explained by the multivalency of g200 on AF molecules and of these on sponge cell surfaces. This polyvalency can be treated from a theoretical viewpoint within the framework of stochastic dynamics of adhesion clusters in the presence of molecular rebinding (Erdmann and Schwarz, 2004) (fig. 5). In the limit of a vanishing force $(F=0)$ the adhesion cluster lifetime $T$ can be calculated as:

$$
T=\frac{1}{1+k_{\text {on }} / k_{\text {off }}}\left[\sum_{n=1}^{N o}\left\{\left(\frac{N_{0} !}{n !\left(N_{0}-n\right) !}\right) \frac{\left(k_{\text {on }} / k_{\text {off }}\right)^{n}}{n}\right\}+H_{N_{0}}\right]
$$

where $N_{0}$ and $H_{N o}$ denote bond number and harmonic numbers (sum of the reciprocals of the first $N_{0}$ natural numbers), respectively. We applied this formula that is based on a stochastic version of Bell's dissociation rate theory $($ Bell, 1978) to extract multivalent lifetimes from straightforward assumptions and our experimental data. Upon assuming a conservative overall number of bonds between two sponge cells of $N_{0}=20-100$ (Garcia-Manyes et al., 2006), a typical rebinding rate of $k_{o n}=0.01 \mathrm{~s}^{-1}$ (Erdmann and Schwarz, 2004), and using our experimental single molecule dissociation rate constants of $k_{\text {off,s.m. }}\left(+\mathrm{Ca}^{2+}\right)$ and $k_{\text {off,s.m. }}\left(-\mathrm{Ca}^{2+}\right)$, we can deduce a multivalent cell aggregation lifetime $\tau_{\text {cell }}\left(+\mathrm{Ca}^{2+}\right)$ of $>10^{15} \mathrm{~s}$ for a calcium-rich $(10 \mathrm{mM})$ and a reduced lifetime $\tau_{\text {cell }}\left(-\mathrm{Ca}^{2+}\right)$ of $<10 \mathrm{~s}$ for a calcium-deficient $(0 \mathrm{mM})$ environment. This simulation result is robust against large variations of $k_{o n}$ and systemic modulations. The assumption to use similar rebinding rate constants for calcium-deficient and calcium-rich 
situations is justified and supported by the experimental fact that under both conditions the overall (re)binding probabilities remain almost constant (fig. S1). 


\section{Discussion}

Calcium binders with biological activity are mainly considered to be proteins, but carbohydrates are emerging as important players in the field, foreseeing the upcoming age of glycomics. In particular, carbohydrate-carbohydrate interactions are being accepted as a novel and highly versatile mechanism for cell adhesion due to the extraordinary plasticity of glycan chains, the low affinity and reversibility of individual binding sites, and the capacity to form multivalent complexes leading to increased association forces (Bucior et al., 2009). Embryogenesis, metastasis, and other cellular proliferation processes are mediated by carbohydrate self-recognition events based on van-der-Waals contacts, hydrogen bonds, and electrostatic forces provided by cations (Hakomori, 1991;Eggens et al., 1989; Yu et al., 2002; Rinaudo, 2006). Carbohydrate-based cell adhesion evolved early, as exemplified by the essential role played by glycan-glycan interactions in sponges, the oldest extant metazoans.

SMFS analysis of intact AF molecules and of g200 glycans has revealed a dependence of their adhesion forces on calcium concentration. In $10 \mathrm{mM} \mathrm{Ca}^{2+}$ an elevated average force with high probability of binding between AFs was measured (Dammer et al., 1995), whereas in $2 \mathrm{mM}$ $\mathrm{Ca}^{2+}$, where sponge cell adhesion is strongly diminished (Cauldwell et al., 1973;Humphreys, 1963; Jumblatt et al., 1980;Misevic and Burger, 1993;Misevic et al., 1987), the force and probability of binding events were also reduced. SMFS measurements of the adhesion forces between single g200 glycans (Bucior and Burger, 2004) showed a significant increase from 310 to $375 \mathrm{pN}$ when the $\mathrm{Ca}^{2+}$ concentration was raised from 10 to $100 \mathrm{mM}$. More recent studies (Garcia-Manyes et al., 2006) revealed a strong $\mathrm{Ca}^{2+}$-dependent cooperative binding in intermolecular adhesion domains of native MAF molecules. Although the calculated mean sponge cell disaggregation time of $10^{15} \mathrm{~s}(\sim 30 \mathrm{Myr})$ in the presence of $10 \mathrm{mM} \mathrm{Ca}^{2+}$ possibly does 
not represent a meaningful number for a sponge individual, it dramatically proves the non-linear and divergent characteristics of the different asymptotic final states upon using physiological parameters in this cooperative model for carbohydrate-carbohydrate binding, which leads to either weakly aggregated cells or stable multicellular assemblies as a function of $\mathrm{Ca}^{2+}$ concentration in the extracellular environment. Apparently small differences in adhesion force between the individual binding sites result in clearly different outcomes when placed in the context of a multivalent system. This suggests that even small variations of oceanic $\mathrm{Ca}^{2+}$ amounts could have had significant effects on the aggregative competency of early metazoan cells. At present, the most generally accepted candidate for causing -or allowing- the Cambrian explosion is a rise in oxygen levels at the end of the Proterozoic (Nursall, 1959). But although oxygen was likely important to permit the existence of large animals, this does not imply that it was also the trigger for their evolution, and we have to consider a complex geochemical setting which should also include other factors such as temperature and salinity (Knauth, 2005).

The data presented here acquire a deep evolutionary significance if one realizes that the content of calcium in sea water has oscillated throughout the different geological periods. One characteristic of the Cambrian explosion fauna is the abundance of animals with calcareous shells (Kerr, 2002), a phenomenon that reflects a well-referenced substantial increase in sea water calcium levels around the beginning of the Cambrian period (Petrychenko et al., 2005;Hardie, 1996;Berner, 2004;Brennan et al., 2004;Elkinton, 1957). Although there is some discrepancy in the literature concerning the precise ion concentration in the oceans at the Precambrian/Cambrian boundary, the generalized calcium surge is an undisputed fact. Many developmental and other physiological processes in animals are calcium-sensitive, from those having calcium as second messenger to biocalcification and cell adhesion. Cellular ion concentrations are under strict control of plasma membrane ion channels that should ward off fluctuations in environmental 
calcium levels. Nevertheless, during the early Cambrian the ambient oceanic calcium may have risen to such a degree that some cells could no longer effectively exclude or expel the $\mathrm{Ca}^{2+}$ ions, causing intracellular calcium in certain marine organisms to reach toxic levels (Simkiss, 1977). The advent of biomineralization (Brennan et al., 2004;Kerr, 2002) might have been a metabolic detoxification process induced by such increases in intracellular $\mathrm{Ca}^{2+}$ (Simkiss, 1977). Opportunistic organisms may have modified existing cellular waste-removal systems by binding $\mathrm{Ca}^{2+}$ as relatively insoluble minerals, which could have been the starting point of the complex process that eventually led to shell production (Simkiss, 1977; Brennan et al., 2004). However, of all cellular functions, cell adhesion was probably the most strongly modulated by even small changes of the calcium concentration in sea water.

We have characterized the adhesion forces of g200 at the contemporary extremes of 0 and $10 \mathrm{mM}$ calcium, although the AFs of $600 \mathrm{Myr}$ ago might have been adapted to work optimally in different salinity conditions. SMFS assays have revealed that AFs from different sponge species having different carbohydrate structures self-bind with similar forces (Bucior et al., 2004). This suggests that carbohydrate interactions have sufficient plasticity to maintain their function by adapting to changing environmental conditions, and therefore that the calcium-dependent binding is a property of AFs throughout the geological eras. So far, orthologues of sponge AF genes have not been identified in other phyla and the closest sequence homology is with a region of the Na$\mathrm{Ca}^{2+}$ exchanger, an ion channel regulating intracellular calcium levels. Thus, the evolutionary role proposed here for AFs was played in primitive sponges or in the stem leading the crown metazoans, and later consolidation of protein-based cell adhesion could explain their absence from more modern animals. Neither is evidence yet for AF precursors in the sister group to the Metazoa, the choanoflagellates, but future research might uncover them. Although protein sequence homologies can be difficult to spot due to the high variability detected for AF genes 
(Fernàndez-Busquets and Burger, 1997), a carbohydrate-based cell aggregation can be expected to be discovered in choanoflagellates. This prediction is founded on the striking morphological and functional resemblance between choanoflagellates and the sponge cell type responsible for food intake, choanocytes, which associate to form choanocyte feeding chambers through AFmediated cell adhesion (Simpson, 1984).

One of the characteristics of the Cambrian explosion is an increased evolution speed, but it is not clear why this evolutionary acceleration should have been favored. Factors such as extreme competition for limited resources or to escape from predators are more likely scenarios after the new phyla occupied most available ecological niches. Alternatively, faster evolution could be the mere by-product of a necessary innovation such as self/non-self recognition. It had been suggested that the capacity of fusion with both kin and genetically unrelated conspecifics to form chimeras is evolutionary retained in several phyla because the resulting organism obtains some selective advantages (Buss, 1982). However, experimental data derived from sponges and colonial marine invertebrates indicate that chimerism does not affect (Maldonado, 1998) or even reduces fitness by causing a decrease in growth rates, reproduction, and survivorship (ChadwickFurman and Weissman, 1995). The extensive allorecognition allele polymorphism commonly observed in natural populations of colonial ascidians and the reported instability of chimeras has led to argue that selection for fusion with self, rather than fusion with kin, may be a major selective force acting on allorecognition systems (Feldgarden and Yund, 1992;Buss, 1982). Self/non-self recognition could have evolved to prevent the costs of germ cell or somatic cell parasitism that can result from the fusion of different individuals while keeping some demographic benefits such as increased size in the event of self-fusion (Stoner and Weissman, 1996). Perhaps tighter links between cells was an important factor in preventing fusion in the first place, a strategy that could have worked in more primitive animals. In agreement with this view, 
the AFs responsible for species-specific cell adhesion in sponges are so polymorphic that they have been suggested to be closely related to the molecules that determine graft rejection and acceptance in these animals (Fernàndez-Busquets and Burger, 1997;Fernàndez-Busquets et al., 1998;Fernàndez-Busquets and Burger, 1999;Fernàndez-Busquets et al., 2002). The correlation between AF protein polymorphism and the outcome of sponge grafts (Fernàndez-Busquets and Burger, 1997), hints at an evolutionary link between early metazoan calcium-dependent cell adhesion and primitive allorecognition molecules that could have preceded histocompatibility systems.

We propose two innovations were necessary for metazoan evolution. First, allorecognition was likely to have evolved as a way of preventing the negative effects of chimerism, e.g. germ cell parasitism or the intrusion of fitness-reducing mutations from a genetically distinct individual. Data from living sponges indicates that sponge larvae may habitually fuse to form viable, genetically hybrid adults (Gauthier and Degnan, 2008;McGhee, 2006), whereas adult sponges possess a precise allorecognition system that efficiently prevents the fusion of different individuals (Sabella et al., 2007;Fernàndez-Busquets and Burger, 1997). This ontogenetic shift might reflect the adoption of improved self/non-self discrimination at some point during primitive sponge evolution prior to the Cambrian explosion. We must assume that the bilaterian lineages started to adopt the mechanism of self/non-self recognition more strictly than sponges do. As a second necessary factor, we suggest that the calcium increase in Cambrian oceans coincided with the existence of primitive sessile metazoans, endowed with allogeneic recognition, and carrying cell adhesion molecules which had significantly longer dissociation times at the new calcium concentrations (fig. 6). Only when calcium levels rose, polyvalent intercellular adhesion became strong enough to allow individual surface-bound metazoans such 
as sponges to maintain their integrity until reproduction. This scenario would permit genetic constitutions to remain within the multicellular individual and be passed down inheritance lines.

Recent evidence clearly places the appearance of sponges during the Cryogenian period, $>635$ Myr ago (Love et al., 2009), whereas the major bursts in animal diversification took place in the next and last Precambrian period, the Ediacaran (Peterson et al., 2008; Shen et al., 2008). However, the body plans characteristic of modern phyla are thought to have evolved gradually somewhat after the time of the Cambrian explosion (Budd, 2008), in an accelerated evolution of the lineages that had already started to diverge earlier (Valentine, 2004). According to current estimates oceanic calcium rose from very low levels around $2 \mathrm{mM}$ (Elkinton, 1957) to reach ca. $10 \mathrm{mM}$ at the Precambrian/Cambrian boundary (Brennan et al., 2004;Berner, 2004), and continued increasing up to concentrations that were higher in early Cambrian oceans than they are at present (Brennan et al., 2004;Petrychenko et al., 2005;Berner, 2004;Hardie, 1996). Thus, with the currently available data presented above on AF function, the effect proposed here for calcium-dependent cell adhesion on the evolution of early metazoans would have been mainly exerted during the Precambrian diversification phase. 


\section{Supplementary Material}

Figures S1 and S2. 


\section{Acknowledgments}

We thank Andrew H. Knoll, Simon Conway-Morris, Flavio S. Anselmetti, Peter Reimann, Robert Ros, Ulrich S. Schwarz and Christoph Pelargus for important and critical discussions and technical support. D.A. and A.K. acknowledge financial support from the Collaborative Research Center SFB 613 from the Deutsche Forschungsgemeinschaft (DFG), and X.F.-B. acknowledges financial support from grants BIO2002-00128, BIO2005-01591, and CSD2006-00012 from the Ministerio de Ciencia y Tecnología, Spain, which included Fondo Europeo de Desarrollo Regional funds, and from grant 2005SGR-00037 from the Generalitat de Catalunya, Spain. 


\section{Figure Legends}

FIG. 1.-Self/non-self recognition in an evolutionary context. (A) Scheme representing the fate of encounters between multicellular aggregates in the absence of self/non-self recognition. (B) Scheme representing how self/non-self recognition could speed up metazoan evolution.

FIG. 2.-Species-specific cell adhesion in sponges is based on calcium-dependent carbohydratecarbohydrate interactions of sponge proteoglycans. (A) Atomic force microscope images of Microciona prolifera aggregation factors (MAF). (B) In its native form, MAF has the structure of a sunburst where the ring is formed by $\sim 20$ units of the MAFp3 protein (empty circles), each noncovalently linked to a unit of the MAFp4 protein (a MAF "arm"). If the ring of MAF were open, the resulting structure is analogous to a classical proteoglycan, with MAFp3 and MAFp4 in place of link protein and proteoglycan monomer, respectively. (C) Model of the MAF interactions responsible for species-specificity of cell adhesion: carbohydrates on MAFp4 bind receptors on the cell membrane whereas the g200 glycan on MAFp3 self-interacts in a calciumdependent manner. For clarity, both MAF molecules are represented linearized.

FIG. 3.-SMFS analysis of the effect of calcium in g200-g200 interactions. (A) Scheme of a SMFS experiment to study the adhesive interactions between two MAF molecules. (B) Typical SMFS approach-retract curve obtained in experiments performed with native MAF, consistent with the cartoon representation from $A$. The numbers from 1 to 13 correspond to the unbinding of individual g200-g200 interactions as the AFM tip retracts from the surface. Adapted from (Garcia-Manyes et al., 2006). (C) Experimental set up showing g200 bound through a polyethylene glycol linker to the AFM tip and surface. (D) Dynamic force spectroscopy graph 
where the measured binding forces in the presence and in the absence of calcium are plotted against the loading rate. The inset shows a typical g200-g200 retracting force curve. Controls performed with linker alone did not reveal significant interactions ( $<0.5 \%$ binding probability) either in the absence or in the presence of calcium.

FIG. 4.-Models summarizing the proposed forces participating in carbohydrate-carbohydrate interactions in the absence $(A)$ and in the presence of calcium $(B)$. In $0 \mathrm{mM} \mathrm{Ca}^{2+}$, excess $\mathrm{Na}^{+}$ions contained in sea water efficiently neutralize the repulsive forces expected from the high negative charge of carboxyl and sulfate groups in g200. Hydrogen bonds are represented by thin arrows and hydrophobic interactions by a ribbon. Adapted from (Spillmann and Burger, 1996).

FIG. 5.-Multivalent calcium-dependent carbohydrate-carbohydrate cell adhesion in metazoan evolution. Scheme of the theoretical model for treating a polyvalent binding mechanism within the framework of stochastic dynamics of adhesion clusters in the presence of molecular dissociation and rebinding.

FIG. 6.-Cartoon summarizing the effect of high and low calcium concentrations on the integrity of primitive sessile metazoans having calcium-dependent cell adhesion molecules. Early metazoans capable of self/non-self discrimination could have developed carbohydrate-based adhesion that at the low calcium content of Precambrian seas was too short-lived to keep cells together for a time long enough to permit the stable persistence of multicellular individuals. 
FIG. S1.-SMFS analysis of g200-g200 interactions. Individual force histograms obtained at different loading rates at $0 \mathrm{mM}$ and $10 \mathrm{mM} \mathrm{Ca}^{2+}$, corresponding to one of the $\mathrm{g} 200-\mathrm{g} 200 \mathrm{SMFS}$ assays performed in this work.

FIG. S2.-Calcium uptake assay. The remaining percentage of initial ${ }^{45}$ Ca radioactivity left in solution is plotted against different incubation times for M. prolifera cells and g200-coated beads in the absence and in the presence of the g200 aggregation inhibitor, monoclonal antibody Block 2. 
Figure 1.

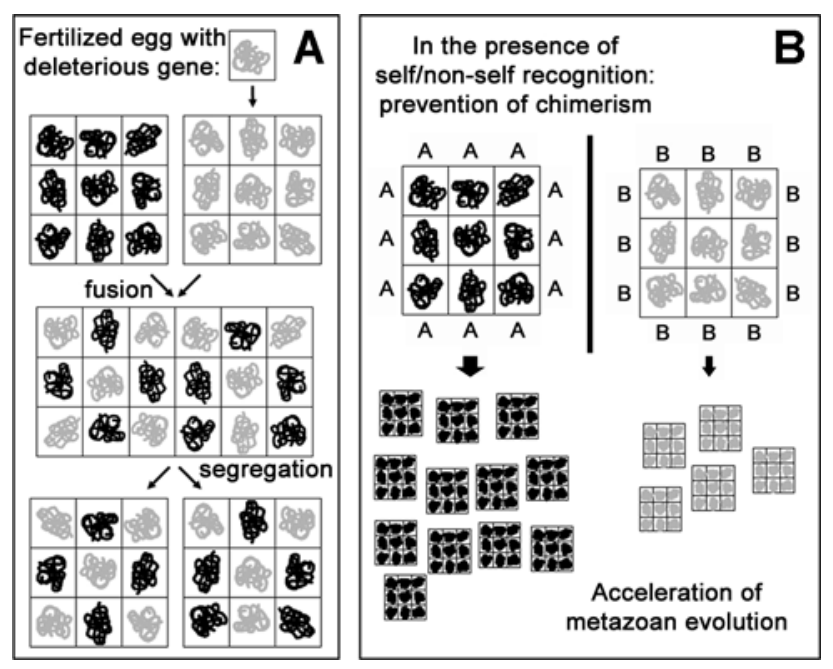


Figure 2.

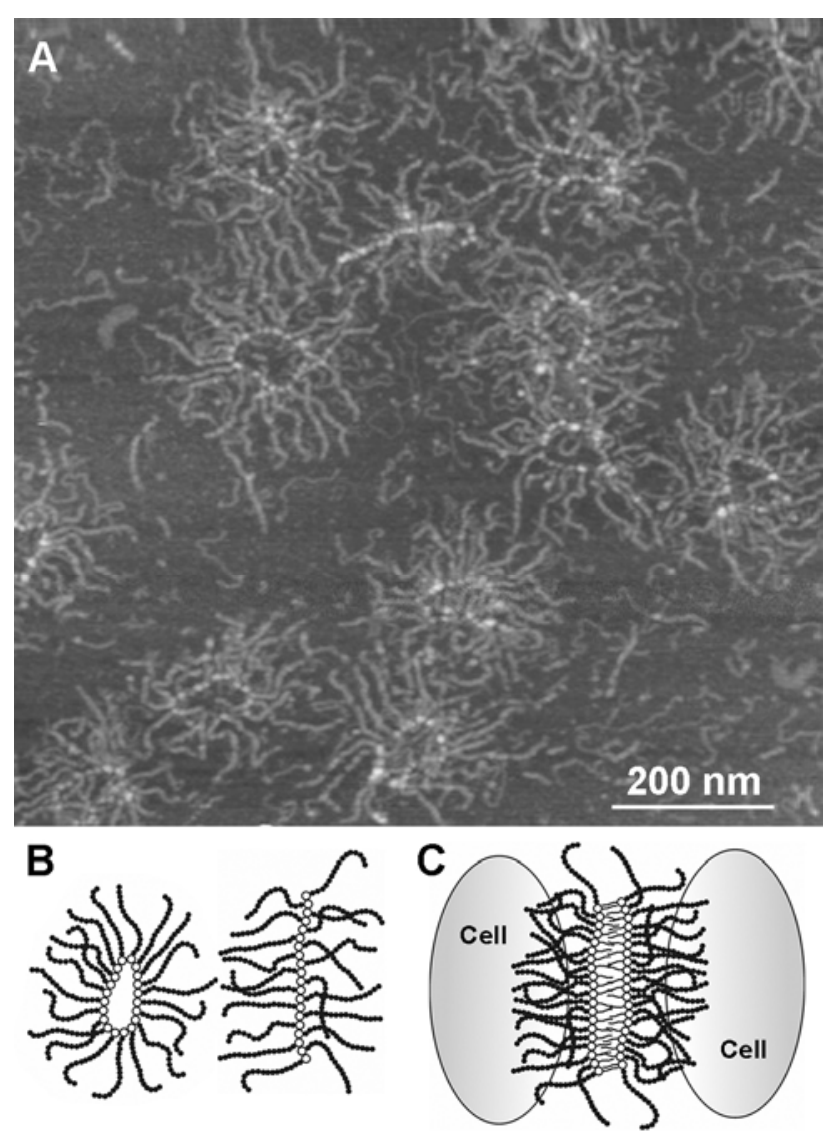


Figure 3.

A
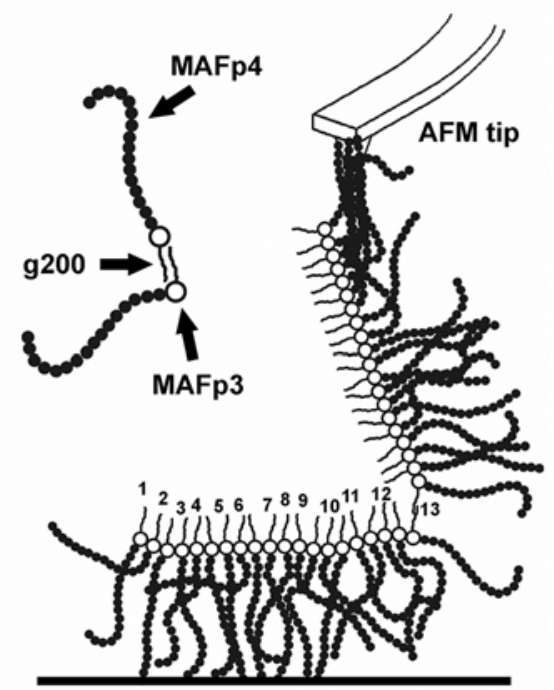

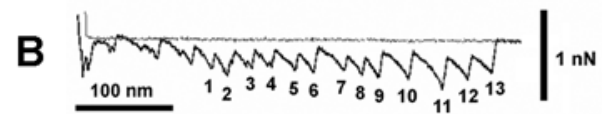

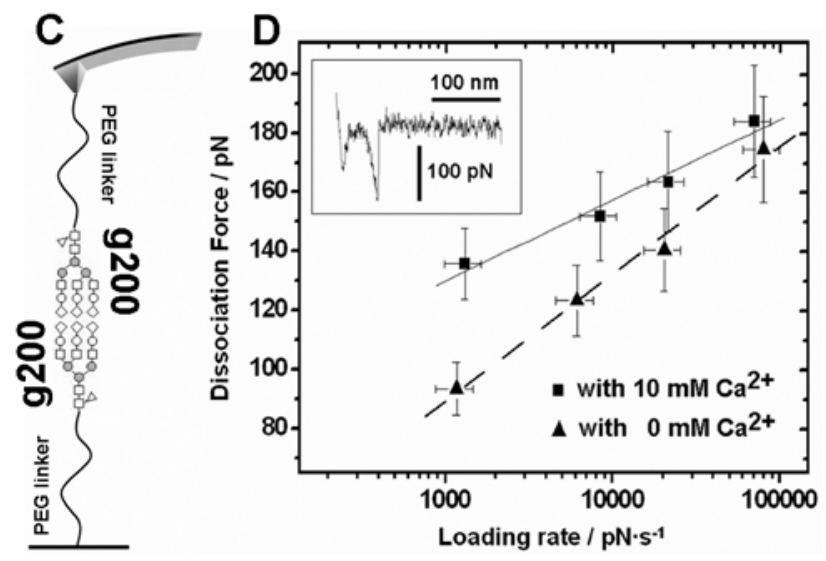


Figure 4.
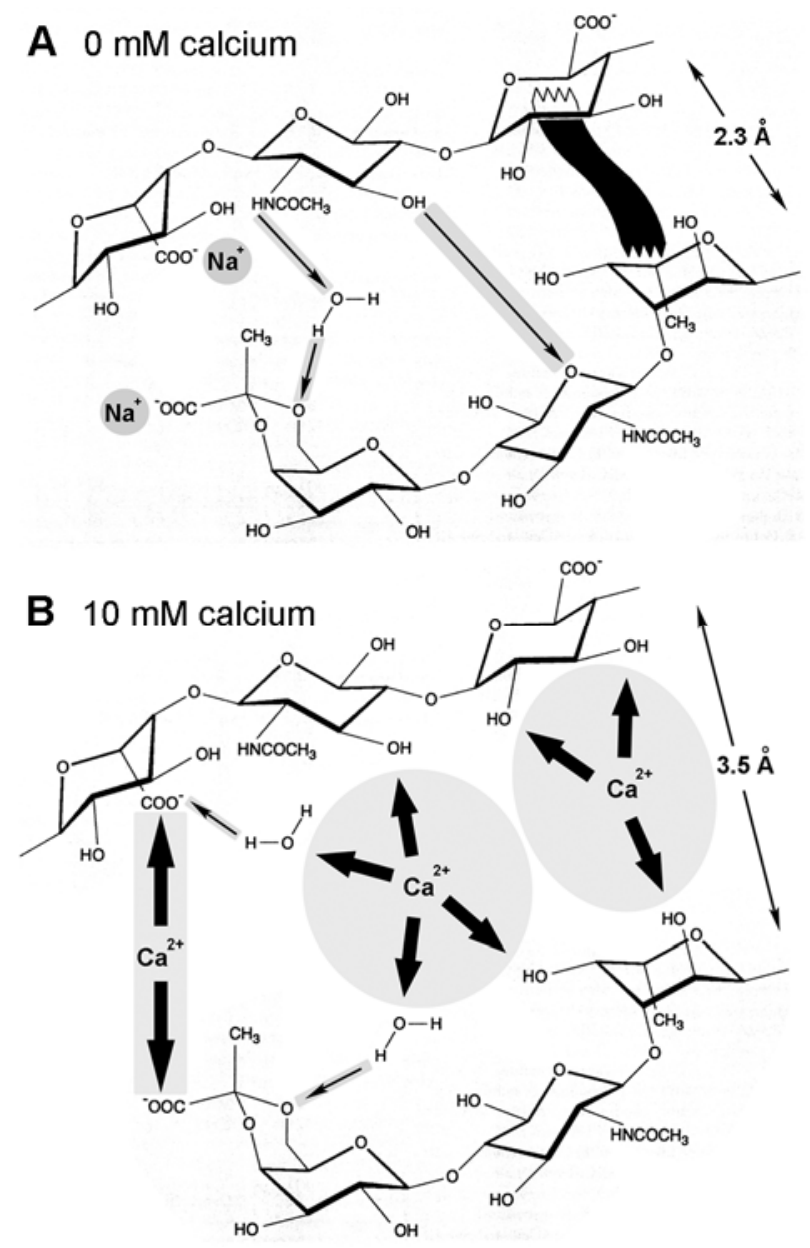
Figure 5.

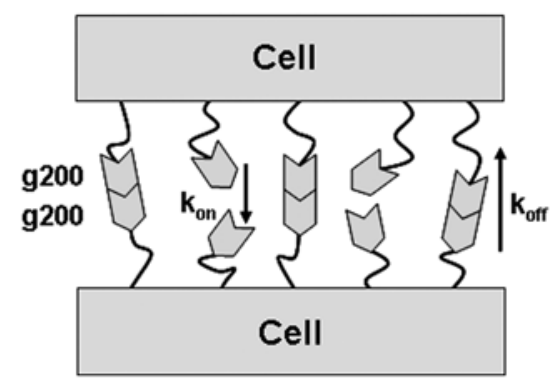


Figure 6.

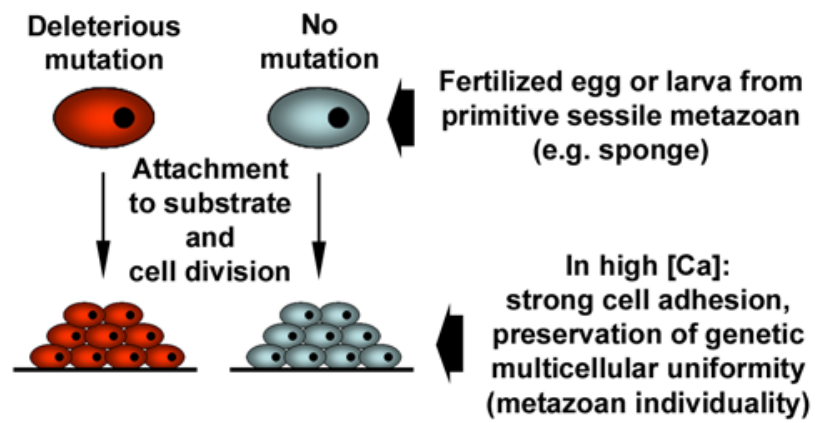

In low [Ca]:

weak cell adhesion, mixed cell aggregates, individuality maintained only at single cell level

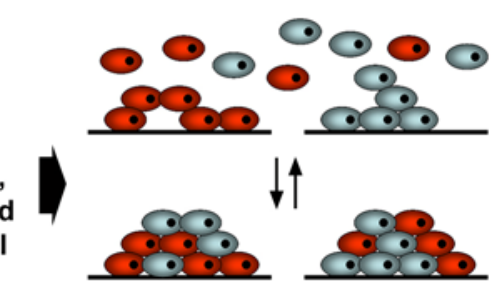


Supplementary Figure 1.
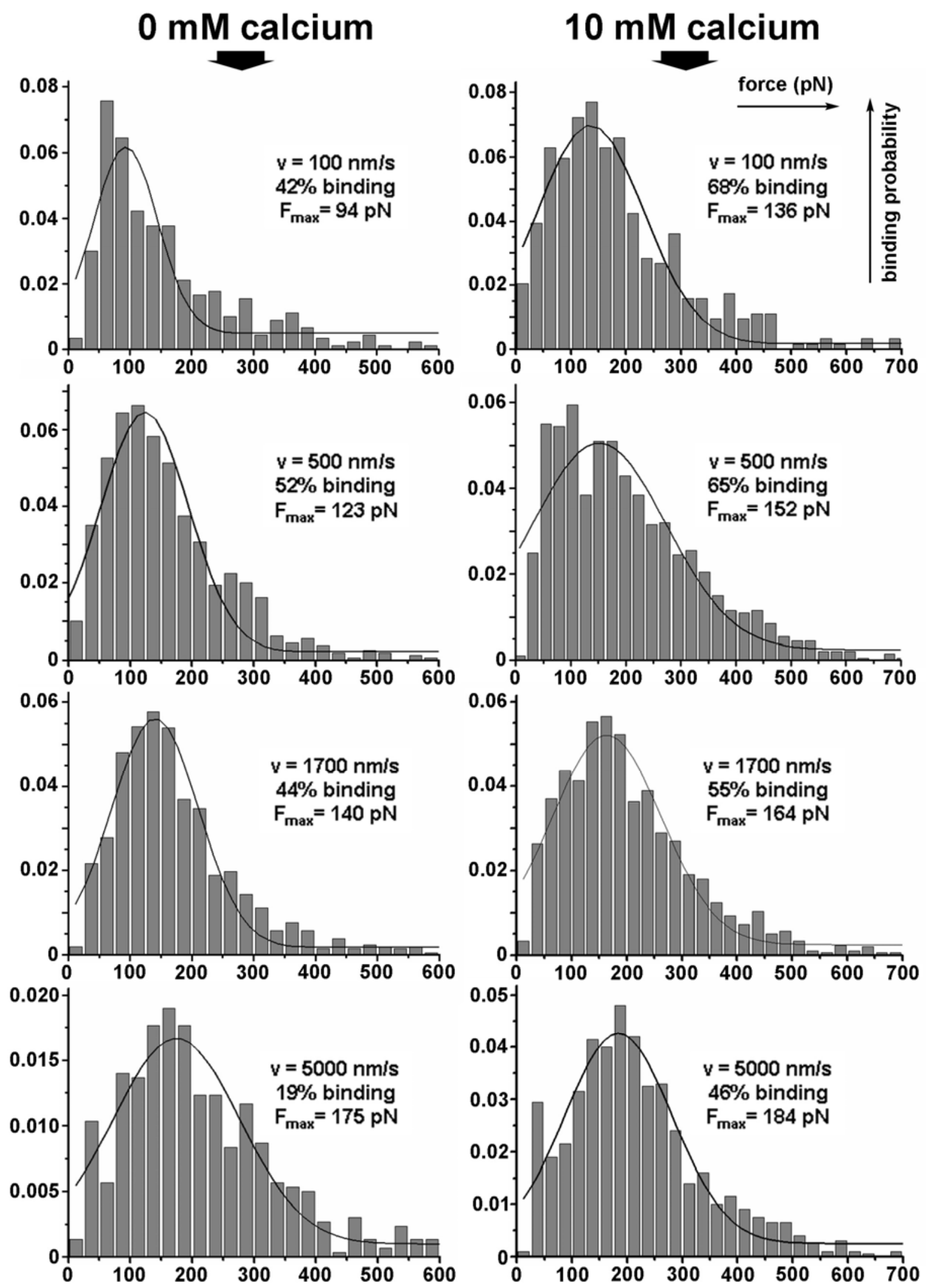
Supplementary Figure 2.

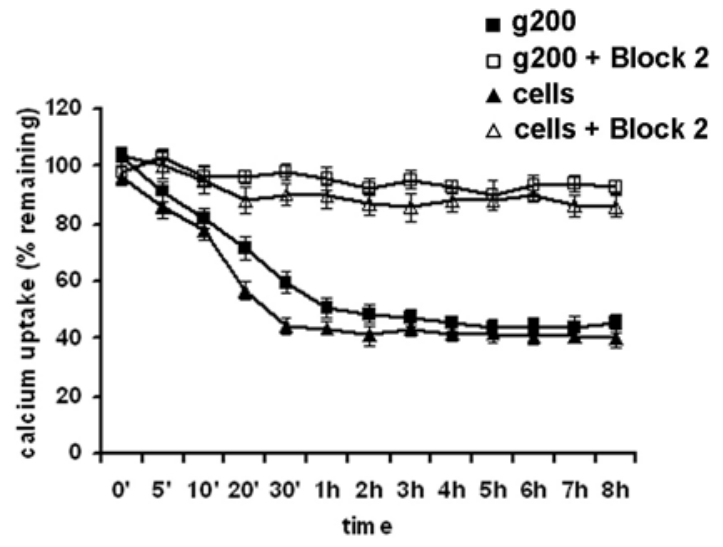




\section{Literature Cited}

Bell GI. 1978. Models for the specific adhesion of cells to cells. Science 200: 618-627.

Berner RA. 2004. A model for calcium, magnesium and sulfate in seawater over Phanerozoic time. Am J Sci 304: 438-453.

Blumbach B, Diehl-Seifert B, Seack J, Steffen R, Müller IM, Müller WE. 1999. Cloning and expression of new receptors belonging to the immunoglobulin superfamily from the marine sponge Geodia cydonium. Immunogenetics 49: 751-763.

Brennan ST, Lowenstein TK, Horita J. 2004. Seawater chemistry and the advent of biocalcification. Geology 32: 473-476.

Bucior I, Burger MM. 2004. Carbohydrate-carbohydrate interaction as a major force initiating cell-cell recognition. Glycoconj J 21: 111-123.

Bucior I, Burger MM, Fernàndez-Busquets X. 2009. Carbohydrate-carbohydrate interactions. In: Gabius H-J, editor. The Sugar Code. Weinheim: WILEY-VCH Verlag GmbH \& Co. KGaA, pp. 347-362.

Bucior I, Scheuring S, Engel A, Burger MM. 2004. Carbohydrate-carbohydrate interaction provides adhesion force and specificity for cellular recognition. J Cell Biol 165: 529-537.

Budd GE. 2008. The earliest fossil record of the animals and its significance. Philos Trans R Soc Lond B Biol Sci 363: 1425-1434.

Buss LW. 1982. Somatic cell parasitism and the evolution of somatic tissue compatibility. Proc Natl Acad Sci USA 79: 5337-5341. 
Cauldwell CB, Henkart P, Humphreys T. 1973. Physical properties of sponge aggregation factor. A unique proteoglycan complex. Biochemistry 12: 3051-3055.

Chadwick-Furman NE, Weissman IL. 1995. Life history plasticity in chimaeras of the colonial ascidian Botryllus schlosseri. Proc R Soc Lond B 262: 157-162.

Conway-Morris S. 2006. Darwin's dilemma: the realities of the Cambrian 'explosion'. Philos Trans R Soc Lond B Biol Sci 361: 1069-1083.

Dammer U, Popescu O, Wagner P, Anselmetti D, Güntherodt HJ, Misevic GN. 1995. Binding strength between cell adhesion proteoglycans measured by atomic force microscopy. Science 267: 1173-1175.

Dawkins R. 1976. The Selfish Gene. Oxford: Oxford University Press.

Dunn CW, Hejnol A, Matus DQ, Pang K, Browne WE, Smith SA, Seaver E, Rouse GW, Obst M, Edgecombe GD, Sørensen MV, Haddock SH, Schmidt-Rhaesa A, Okusu A, Kristensen RM, Wheeler WC, Martindale MQ, Giribet G. 2008. Broad phylogenomic sampling improves resolution of the animal tree of life. Nature 452: 745-749.

Eckel R, Ros R, Decker B, Mattay J, Anselmetti D. 2005. Supramolecular chemistry at the single-molecule level. Angew Chem Int Ed Engl 44: 484-488.

Eggens I, Fenderson B, Toyokuni T, Dean B, Stroud M, Hakomori S. 1989. Specific interaction between Lex and Lex determinants. A possible basis for cell recognition in preimplantation embryos and in embryonal carcinoma cells. J Biol Chem 264: 9476-9484.

Elkinton JR. 1957. The relationship of water and salt. Proc Nutr Soc 16: 113-118. 
Erdmann T, Schwarz US. 2004. Stochastic dynamics of adhesion clusters under shared constant force and with rebinding. J Chem Phys 121: 8997-9017.

Evans E, Ritchie K. 1997. Dynamic strength of molecular adhesion bonds. Biophys J 72: 15411555.

Feldgarden M, Yund PO. 1992. Allorecognition in colonial marine invertebrates: does selection favor fusion with kin or fusion with self? Biol Bull 182: 155-158.

Fernàndez-Busquets X. 2008. The Sponge as a Model of Cellular Recognition. In: Conn PM, editor. Sourcebook of Models for Biomedical Research. Totowa, NJ, USA: Humana Press Inc., pp. 75-83.

Fernàndez-Busquets X, Burger MM. 1997. The main protein of the aggregation factor responsible for species-specific cell adhesion in the marine sponge Microciona prolifera is highly polymorphic. J Biol Chem 272: 27839-27847.

Fernàndez-Busquets X, Burger MM. 1999. Cell adhesion and histocompatibility in sponges. Microsc Res Tech 44: 204-218.

Fernàndez-Busquets X, Burger MM. 2003. Circular proteoglycans from sponges: first members of the spongican family. Cell Mol Life Sci 60: 88-112.

Fernàndez-Busquets X, Gerosa D, Hess D, Burger MM. 1998. Accumulation in marine sponge grafts of the mRNA encoding the main proteins of the cell adhesion system. J Biol Chem 273: 29545-29553. 
Fernàndez-Busquets X, Kuhns WJ, Simpson TL, Ho M, Gerosa D, Grob M, Burger MM. 2002. Cell adhesion-related proteins as specific markers of sponge cell types involved in allogeneic recognition. Dev Comp Immunol 26: 313-323.

Fritz J, Anselmetti D, Jarchow J, Fernàndez-Busquets X. 1997. Probing single biomolecules with atomic force microscopy. J Struct Biol 119: 165-171.

Garcia-Manyes S, Bucior I, Ros R, Anselmetti D, Sanz F, Burger MM, Fernàndez-Busquets X. 2006. Proteoglycan mechanics studied by single-molecule force spectroscopy of allotypic cell adhesion glycans. J Biol Chem 281: 5992-5999.

Gauthier M, Degnan BM. 2008. Partitioning of genetically distinct cell populations in chimeric juveniles of the sponge Amphimedon queenslandica. Dev Comp Immunol 32: 1270-1280.

Hakomori S. 1991. Carbohydrate-carbohydrate interaction as a initial step in cell recognition. Pure Appl Chem 63: 473-482.

Hardie LA. 1996. Secular variation in seawater chemistry; an explanation for the coupled secular variation in the mineralogies of marine limestones and potash evaporites over the past 600 m.y. Geology 24: 279-283.

Hinterdorfer P, Baumgartner W, Gruber HJ, Schilcher K, Schindler H. 1996. Detection and localization of individual antibody-antigen recognition events by atomic force microscopy. Proc Natl Acad Sci USA 93: 3477-3481.

Humphreys T. 1963. Chemical dissolution and in vitro reconstruction of sponge cell adhesions. I. Isolation and functional demonstration of the components involved. Dev Biol 8: 27-47. 
Hutter JL, Bechhofer J. 1993. Calibration of atomic force microscope tips. Rev Sci Instrum 64: 1868-1873.

Jarchow J, Fritz J, Anselmetti D, Calabro A, Hascall VC, Gerosa D, Burger MM, FernàndezBusquets X. 2000. Supramolecular structure of a new family of circular proteoglycans mediating cell adhesion in sponges. J Struct Biol 132: 95-105.

Jumblatt JE, Schlup V, Burger MM. 1980. Cell-cell recognition: specific binding of Microciona sponge aggregation factor to homotypic cells and the role of calcium ions. Biochemistry 19: 1038-1042.

Kerr RA. 2002. Paleoceanography. Inconstant ancient seas and life's path. Science 298: 11651166.

Knauth LP. 2005. Temperature and salinity history of the Precambrian ocean: implications for the course of microbial evolution. Palaeogeogr Palaeoclimatol Palaeoecol 219: 53-59.

Kruse M, Steffen R, Batel R, Müller IM, Müller WE. 1999. Differential expression of allograft inflammatory factor 1 and of glutathione peroxidase during auto- and allograft response in marine sponges. J Cell Sci 112: 4305-4313.

Kuusksalu A, Pihlak A, Müller WE, Kelve M. 1995. The (2'-5')oligoadenylate synthetase is present in the lowest multicellular organisms, the marine sponges. Demonstration of the existence and identification of its reaction products. Eur J Biochem 232: 351-357.

Love GD, Grosjean E, Stalvies C, Fike DA, Grotzinger JP, Bradley AS, Kelly AE, Bhatia M, Meredith W, Snape CE, Bowring SA, Condon DJ, Summons RE. 2009. Fossil steroids record the appearance of Demospongiae during the Cryogenian period. Nature 457: 718-721. 
Lyubchenko Y, Shlyakhtenko L, Harrington R, Oden P, Lindsay S. 1993. Atomic force microscopy of long DNA: imaging in air and under water. Proc Natl Acad Sci USA 90: 21372140.

Maldonado M. 1998. Do chimeric sponges have improved chances of survival? Mar Ecol Prog Ser 164: 301-306.

Marshall CR. 2006. Explaining the Cambrian "explosion" of animals. Annu Rev Earth Planet Sci 34: $355-384$.

Mathews CK, van Holde KE. 1990. Biochemistry. San Francisco, CA, USA: The Benjamin/Cummings Publishing Company, Inc.

McGhee KE. 2006. The importance of life-history stage and individual variation in the allorecognition system of a marine sponge. J Exp Mar Biol Ecol 333: 241-250.

Misevic GN, Burger MM. 1993. Carbohydrate-carbohydrate interactions of a novel acidic glycan can mediate sponge cell adhesion. J Biol Chem 268: 4922-4929.

Misevic GN, Finne J, Burger MM. 1987. Involvement of carbohydrates as multiple low affinity interaction sites in the self-association of the aggregation factor from the marine sponge Microciona prolifera. J Biol Chem 262: 5870-5877.

Müller WE. 2001. How was metazoan threshold crossed? The hypothetical Urmetazoa. Comp Biochem Physiol A Mol Integr Physiol 129: 433-460. 
Müller WE, Perovic S, Wilkesman J, Kruse M, Müller IM, Batel R. 1999. Increased gene expression of a cytokine-related molecule and profilin after activation of Suberites domuncula cells with xenogeneic sponge molecule(s). DNA Cell Biol 18: 885-893.

Müller WE, Schröder HC, Skorokhod A, Bünz C, Müller IM, Grebenjuk VA. 2001. Contribution of sponge genes to unravel the genome of the hypothetical ancestor of Metazoa (Urmetazoa). Gene 276: 161-173.

Müller WEG, Müller IM. 2003. Origin of the metazoan immune system: identification of the molecules and their functions in sponges. Integr Comp Biol 43: 281-292.

Nursall JR. 1959. Oxygen as a prerequisite to the origin of the Metazoa. Nature 183: 1170-1172.

Pahler S, Blumbach B, Müller I, Müller WE. 1998. Putative multiadhesive protein from the marine sponge Geodia cydonium: cloning of the cDNA encoding a fibronectin-, an SRCR-, and a complement control protein module. J Exp Zool 282: 332-343.

Pancer Z, Skorokhod A, Blumbach B, Müller WE. 1998. Multiple Ig-like featuring genes divergent within and among individuals of the marine sponge Geodia cydonium. Gene 207: $227-233$.

Peterson KJ, Cotton JA, Gehling JG, Pisani D. 2008. The Ediacaran emergence of bilaterians: congruence between the genetic and the geological fossil records. Philos Trans R Soc Lond B Biol Sci 363: 1435-1443.

Petrychenko OY, Peryt TM, Chechel EI. 2005. Early Cambrian seawater chemistry from fluid inclusions in halite from Siberian evaporites. Chem Geol 219: 149-161. 
Rice DJ, Humphreys T. 1983. Two $\mathrm{Ca}^{2+}$ functions are demonstrated by the substitution of specific divalent and lanthanide cations for the $\mathrm{Ca}^{2+}$ required by the aggregation factor complex from the marine sponge, Microciona prolifera. J Biol Chem 258: 6394-6399.

Rinaudo M. 2006. Non-covalent interactions in polysaccharide systems. Macromol Biosci 6: 590610.

Sabella C, Faszewski E, Himic L, Colpitts KM, Kaltenbach J, Burger MM, Fernàndez-Busquets X. 2007. Cyclosporin A suspends transplantation reactions in the marine sponge Microciona prolifera. J Immunol 179: 5927-5935.

Sakarya O, Armstrong KA, Adamska M, Adamski M, Wang IF, Tidor B, Degnan BM, Oakley TH, Kosik KS. 2007. A post-synaptic scaffold at the origin of the animal kingdom. PLoS ONE 2: e506.

Schwesinger F, Ros R, Strunz T, Anselmetti D, Güntherodt HJ, Honegger A, Jermutus L, Tiefenauer L, Pluckthun A. 2000. Unbinding forces of single antibody-antigen complexes correlate with their thermal dissociation rates. Proc Natl Acad Sci USA 97: 9972-9977.

Shen B, Dong L, Xiao S, Kowalewski M. 2008. The Avalon explosion: evolution of Ediacara morphospace. Science 319: 81-84.

Simkiss K. 1977. Biomineralization and detoxification. Calcif Tissue Res 24: 199-200.

Simpson TL. 1984. The cell biology of sponges. New York: Springer-Verlag.

Spillmann D, Burger MM. 1996. Carbohydrate-carbohydrate interactions in adhesion. J Cell Biochem 61: 562-568. 
Steinberg MS, Garrod DR. 1975. Observations on the sorting-out of embryonic cells in monolayer culture. J Cell Sci 18: 385-403.

Stoner DS, Weissman IL. 1996. Somatic and germ cell parasitism in a colonial ascidian: possible role for a highly polymorphic allorecognition system. Proc Natl Acad Sci USA 93: 1525415259.

Valentine JW. 2004. On the origin of phyla. Chicago: The University of Chicago Press.

Wiens M, Korzhev M, Perovic-Ottstadt S, Luthringer B, Brandt D, Klein S, Müller WE. 2007. Toll-like receptors are part of the innate immune defense system of sponges (demospongiae: Porifera). Mol Biol Evol 24: 792-804.

Yu S, Kojima N, Hakomori SI, Kudo S, Inoue S, Inoue Y. 2002. Binding of rainbow trout sperm to egg is mediated by strong carbohydrate-to-carbohydrate interaction between (KDN)GM3 (deaminated neuraminyl ganglioside) and Gg3-like epitope. Proc Natl Acad Sci USA 99: 2854-2859. 